\title{
An Improved Mathematical Model for Computing Power Output of Solar Photovoltaic Modules
}

\author{
Abdul Qayoom Jakhrani, ${ }^{1}$ Saleem Raza Samo, ${ }^{1}$ Shakeel Ahmed Kamboh, \\ Jane Labadin, ${ }^{3}$ and Andrew Ragai Henry Rigit ${ }^{4}$ \\ ${ }^{1}$ Energy and Environment Engineering Department, Quaid-e-Awam University of Engineering, \\ Science and Technology (QUEST), Nawabshah, Sindh 67480, Pakistan \\ ${ }^{2}$ Department of Mathematics and Computational Science, Faculty of Computer Science and Information Technology, \\ Universiti Malaysia Sarawak, Kota Samarahan, 94300 Sarawak, Malaysia \\ ${ }^{3}$ Faculty of Computer Science and Information Technology, Universiti Malaysia Sarawak, Kota Samarahan, \\ 94300 Sarawak, Malaysia \\ ${ }^{4}$ Faculty of Engineering, Universiti Malaysia Sarawak, Kota Samarahan, 94300 Sarawak, Malaysia
}

Correspondence should be addressed to Abdul Qayoom Jakhrani; aqunimas@hotmail.com

Received 31 May 2013; Revised 26 December 2013; Accepted 9 January 2014; Published 17 March 2014

Academic Editor: Ismail H. Altas

Copyright (C) 2014 Abdul Qayoom Jakhrani et al. This is an open access article distributed under the Creative Commons Attribution License, which permits unrestricted use, distribution, and reproduction in any medium, provided the original work is properly cited.

It is difficult to determine the input parameters values for equivalent circuit models of photovoltaic modules through analytical methods. Thus, the previous researchers preferred to use numerical methods. Since, the numerical methods are time consuming and need long term time series data which is not available in most developing countries, an improved mathematical model was formulated by combination of analytical and numerical methods to overcome the limitations of existing methods. The values of required model input parameters were computed analytically. The expression for output current of photovoltaic module was determined explicitly by Lambert W function and voltage was determined numerically by Newton-Raphson method. Moreover, the algebraic equations were derived for the shape factor which involves the ideality factor and the series resistance of a single diode photovoltaic module power output model. The formulated model results were validated with rated power output of a photovoltaic module provided by manufacturers using local meteorological data, which gave $\pm 2 \%$ error. It was found that the proposed model is more practical in terms of precise estimations of photovoltaic module power output for any required location and number of variables used.

\section{Introduction}

The photovoltaic (PV) modules are generally rated under standard test conditions (STC) with the solar radiation of $1000 \mathrm{~W} / \mathrm{m}^{2}$, cell temperature of $25^{\circ} \mathrm{C}$, and solar spectrum of 1.5 by the manufacturers. The parameters required for the input of the PV modules are relying on the meteorological conditions of the area. The climatic conditions are unpredictable due to the random nature of their occurrence. These uncertainties lead to either over- or underestimation of energy yield from PV modules. An overestimation up to $40 \%$ was reported as compared to the rated power output of PV modules [1,2]. The growing demand of photovoltaics technologies led to research in the various aspects of its components from cell technology to the modeling, size optimization, and system performance [3-5]. Modeling of $\mathrm{PV}$ modules is one of the major components responsible for proper functioning of PV systems. Modeling provides the ways to understand the current, voltage, and power relationships of PV modules [6-8]. However, the estimation of models is affected by various intrinsic and extrinsic factors, which ultimately influence the behavior of current and voltage. Therefore, perfect modeling is essential to estimate the performance of PV modules in different environmental conditions. Hernanz et al. [9] compared the performance of solar cells with different models and pointed out that the manufacturers did not provide the values of the resistance in series and parallel of the manufactured cell. Andrews et al. [10] proposed an improved methodology for fine resolution modeling of PV systems using module short circuit current 
$\left(I_{\text {sc }}\right)$ at $5 \mathrm{~min}$ time scales. Their work was a modified version of the Sandia array performance model by incorporating new factors for the calculation of short circuit current $\left(I_{\mathrm{sc}}\right)$ to justify errors (including instrumentation alignment and spectral and module power tolerance errors). Chakrasali et al. [11] investigated the performance of Norton's circuit model of solar PV module with the existing models using Matlab and reported that it is a well-suited way to predict the behavior of PV modules operated for longer periods of time. Chouder et al. [12] modeled a PV module by a single diode lumped circuit and evaluated its main parameters by considering the power conversion efficiency. Chouder et al. [13] presented a detailed characterization of the performance and dynamic behavior of PV systems by using the LabVIEW platform. The Lambert $\mathrm{W}$ function was applied for the solution of equations by Jain and Kapoor [14], Jain et al. [15], Ortiz-Conde et al. [16], and others [17-19]. Picault et al. [17] presented a novel method to forecast existing PV array production in diverse environmental conditions and concluded that Lambert $\mathrm{W}$ function facilitates a direct relationship between current and voltage of modules as it significantly reduces calculation time. Chen et al. [18] proposed an optimized method based on polynomial curve fitting and Lambert $\mathrm{W}$ function for extraction of parameters from the current-voltage $(I-V)$ characteristics of commercial silicon solar cells. The Lambert $\mathrm{W}$ function was used for translation of transcendental equation into explicit analytical solution. Fathabadi [19] presented a novel method for characterization of silicon solar cells, modules, and plastic solar cells. Artificial neural network together with Lambert $\mathrm{W}$ function was employed for determination of $I-V$ and $P-V$ curves of silicon and plastic solar cells and modules [20].

Moreover, Krismadinata et al. [21] used a single diode electrical equivalent circuit model for determination of PV cell characteristics and found that output of PV modules were strongly affected by the intensity of solar irradiation and ambient temperature. Lu et al. [22] investigated various PV module layouts using full size as well as halved solar cells. The performance of module layouts was investigated by partially shading the PV cells using a solar cell equivalent circuit model with SPICE software. They found that the series-parallel hybrid connection of cells within a module has a significant improvement on the power output of the PV module under partial shading conditions. Mellit et al. [23] employed a methodology for estimation power profile of a $50 \mathrm{Wp}$ Si-polycrystalline PV module by developing two artificial neural networks (ANNs) for cloudy and sunny days and found that the ANN-models performed better than the existing models and also did not need more parameters unlike implicit models. Singh [24] reviewed various models of PV cells and concluded that the accuracy of models can be improved by including series and shunt resistance into the model. In addition, the author also discovered that the estimation of models can further be improved by either introducing two parallel diodes with independent set saturation current or considering the diode quality factor as a variable parameter instead of fixed value like 1 or 2 . Thevenard and Pelland [25] reported that the uncertainties of model predictions can be reduced by increasing the reliability and spatial coverage of solar radiation estimates, appropriate familiarity of losses due to dirt, soiling, and snow, and development of better tools for PV system modeling. Tian et al. [26] presented a modified $I-V$ relationship for the single diode model. The alteration in the model was made in the parallel and series connections of an array. The derivation of the adapted $I-V$ relationship was begun with a single solar cell and extended up to a PV module and finally an array. The modified correlation was investigated with a five-parameter model based on the data provided by the manufacturers. The performance of the model was examined with a wide range of irradiation levels and cell temperatures for prediction of $I-V$ and $P-V$ curves, maximum power point values, short circuit current, and open circuit voltage. Vincenzo and Infield [27] developed a detailed PV array model to deal explicitly with nonuniform irradiance and other nonuniformities across the array and it was validated against data from an outdoor test system. However, the authors reduced the complexity of the simulations by assuming that the cell temperatures are homogeneous for each module. Yordanov et al. [28] presented a new algorithm for determination of the series resistance of crystalline-Si PV modules from individual illuminated $I-V$ curves. The ideality factor and the reverse saturation current were extracted in the typical way. They found that the ideality factor at open circuit is increased by about $5 \%$. It was established from the review that Lambert $\mathrm{W}$ function is a simple technique to give the analytical explicit solution of solar photovoltaic module characteristics as compared to the other methods. However, some problems still exist for the derivation of the required model equations.

Equivalent electrical circuit model is one of the key models under study since the last few decades. It is configured with either single or double diode for investigation of currentvoltage relationships. The single diode models usually have five, four, or three unknown parameters with only one exponential term. The five unknown parameters of a single diode model are light-generated current $\left(I_{L}\right)$, diode reverse saturation current $\left(I_{o}\right)$, series resistance $\left(R_{s}\right)$, shunt resistance $\left(R_{\mathrm{sh}}\right)$, and diode ideality factor $(A)[29,30]$. The fourparameter model infers the shunt resistance as infinite and it is ignored [31]. The three-parameter model assumes that the series resistance is zero and shunt resistance is infinite and, thus, both of these parameters are ignored, whereas, the double diode models have six unknown parameters with two exponential terms [32, 33].

In fact, both single and double diode models require the knowledge of all unknown parameters, which is usually not provided by manufacturers. Nevertheless, the current-voltage equation is a transcendental expression. It has no explicit analytical solution. It is also time consuming to discover its exact analytical solution due to the limitation of available data for the extraction of required parameters [34-36]. For that reason, the researchers gradually focused on searching out the approximate methods for the calculation of unknown parameters. The analytical methods give exact solutions by means of algebraic equations. However, due to implicit nature and nonlinearity of PV cell or module characteristics, it is hard to find out the analytical solution of all unknown parameters. Analytical methods have also some limitations and could not give exact solutions when the functions 
are not given. Thus, numerical methods such as NewtonRaphson method or Levenberg-Marquardt algorithm were preferred. It is because of the fact that numerical methods give approximate solution of the nonlinear problems without searching for exact solutions. However, numerical methods are time consuming and need long term time series data which is not available in developing countries.

It was revealed from the review that a wide variety of models exist for estimation of power output of PV modules. However, these were either complicated or gave approximate solutions. To overcome the limitations of both numerical and analytical methods an improved mathematical model using combination of numerical and analytical methods is presented. It makes the model simple as well as comprehensive to provide acceptable estimations for PV module power outputs. The values of required unknown parameters of $I-V$ curve, namely, light-generated current, diode reverse saturation current, shape parameter, and the series resistance, are computed analytically. The expression for output current of PV module is determined explicitly by Lambert W function and voltage output is computed numerically by NewtonRaphson method.

\section{Formulated Model for Computing Power Output of PV Modules}

The power produced by a PV module depends on intrinsic electrical characteristics (current and voltage) and extrinsic atmospheric conditions. The researchers generally incorporate the most important electrical characteristics and influential meteorological parameters in the models for the sake of simplicity. It is almost unfeasible to obtain a model that accounts each parameter which influences the performance of PV modules. The models generally include those parameters, which are commonly provided by manufacturers, such as the electrical properties of modules at standard rating conditions [37]. The standard equivalent electrical circuit model of PV cell denoted by a single diode is expressed as [38]

$$
I=I_{L}-I_{D}-I_{\mathrm{sh}} \text {, }
$$

where $I_{L}$ is light-generated current, $I_{D}$ is diode current, and $I_{\text {sh }}$ is shunt current. The diode current $\left(I_{D}\right)$ is expressed by the Shockley equation as $[39,40]$ :

$$
I_{D}=I_{o}\left[e^{\xi\left(V+I R_{s}\right)}-1\right]
$$

The shunt current $\left(I_{\text {sh }}\right)$ is defined by Petreus et al. [41] as

$$
I_{\mathrm{sh}}=\frac{V+I R_{s}}{R_{\mathrm{sh}}} .
$$

Therefore, the final structure of five-parameter one diode electrical equivalent circuit model is graphically shown in Figure 1. It is also algebraically expressed as [40, 42-44]

$$
I=I_{L}-I_{o}\left[e^{\xi\left(V+I R_{s}\right)}-1\right]-\frac{V+I R_{s}}{R_{\mathrm{sh}}},
$$

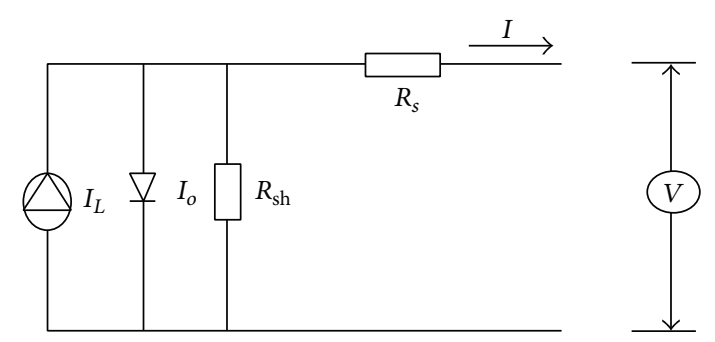

FIGURE 1: Equivalent electrical circuit model of a PV module.

where $I_{o}$ is the reverse saturation current and $\xi$ is a term incorporated for the simplicity of (4), which is expressed as

$$
\xi=\frac{q}{\lambda k T_{c}}
$$

where $q$ is electronic charge, $k$ is Boltzmann's constant, $T_{c}$ is the cell temperature, and $\lambda$ is the shape factor, which is given as

$$
\lambda=A \times N_{\mathrm{CS}}
$$

where $A$ is the ideality factor and $N_{C S}$ is the number of series cells in a module. The ideality factor $(A)$ does not depend on the temperature as per definition of shape factor $(\lambda)$ from semiconductor theory [45]. The five unknown parameters, namely, $I_{L}, I_{o}, R_{s}, R_{\mathrm{sh}}$, and $A$, can only be found through complicated numerical methods from a nonlinear solar cell equation. It requires a close approximation of initial parameter values to attain convergence. Otherwise, the result may deviate from the real values $[32,43]$. It is impractical to find a method, which can properly extract all required parameters to date $[40,46]$. Thus, for simplicity, the shunt resistance $\left(R_{\mathrm{sh}}\right)$ is assumed to be infinity. Hence, the last term in (4) is ignored [47]. Therefore, the simplified form of fourparameter single diode equivalent circuit model, which is used for this study, is defined as [48]

$$
I=I_{L}-I_{o}\left[e^{\xi\left(V+I R_{s}\right)}-1\right] .
$$

From (7), a continuous relationship of current as function of voltage for a given solar irradiance, cell temperature, and other cell parameters can be obtained.

\subsection{Determination of Unknown Parameters of Formulated} Model. The expressions for unknown parameters such as light-generated current $\left(I_{L}\right)$ and reverse saturation current $\left(I_{o}\right)$ were adopted from previous available models. The expressions for the shape factor $(\lambda)$ which involve the ideality factor $(A)$ and the series resistance $\left(R_{s}\right)$ were algebraically derived from existing equations. The PV module used for this study was NT-175 (E1) manufactured by Sharp Energy Solution Europe, a division of Sharp Electronics (Europe) GmbH, Sonninstraße 3, 20097, Hamburg, Germany.

2.1.1. Light-Generated Current $\left(I_{L}\right)$. Light-generated current $\left(I_{L}\right)$ is a function of solar radiation and module temperature, 
if the series resistance $\left(R_{s}\right)$ and the shape factor $(\lambda)$ are taken as constants. For any operating condition, $I_{L}$ is related to the light-generated current measured at some reference conditions as $[14,29]$

$$
I_{L}=\left(\frac{S_{T}}{S_{T, r}}\right)\left[I_{L, r}+\mu_{I_{\mathrm{sc}}}\left(T_{c}-T_{c, r}\right)\right],
$$

where $S_{T}$ and $S_{T, r}$ are the absorbed solar radiation and $T_{c}$ and $T_{c, r}$ are the cell temperatures at outdoor conditions and reference conditions, respectively. $I_{L, r}$ is light-generated current at reference conditions and $\mu_{I_{\mathrm{sc}}}$ is coefficient of temperature at short circuit current. The cell temperature $\left(T_{c}\right)$ can be computed from the ambient temperature and other data tested at nominal operating cell temperature (NOCT) conditions, provided by the manufacturers.

2.1.2. Reverse Saturation Current $\left(I_{o}\right)$. The reverse saturation current $\left(I_{o}\right)$ is a function of temperature only [49]. It is given as

$$
I_{o}=D T_{c}^{3} e^{\xi \varepsilon_{g} / A}
$$

The reverse saturation current $\left(I_{o}\right)$ is a diminutive number, but its value increases by a factor of two with a temperature increase of $10^{\circ} \mathrm{C}$ [50]. It is actually computed by taking the ratio of (9) at two different temperatures, thereby, eliminating the diode diffusion factor $(D)$. It is related to the temperature only. Thus, it is estimated at some reference conditions as the same technique used for the determination of light current [49]. Consider

$$
I_{o}=\left(\frac{T_{c}}{T_{c, r}}\right)^{3} e^{\xi \lambda \varepsilon_{g}\left(T_{c, r}-T_{c}\right) / A}
$$

2.1.3. Shape Factor $(\lambda)$. Mostly, manufacturers provide information of $I-V$ characteristic curve at three different points using reference conditions, at open circuit voltage $\left(V_{\mathrm{oc}}\right)$, at short circuit current $\left(I_{\mathrm{sc}}\right)$, and at optimum power point for both current and voltage. The correlation for the given points are $I=0$ and $V=V_{\mathrm{oc}}$ at open circuit conditions, $I=I_{\mathrm{sc}}$ and $V=0$ at short circuit conditions, and $I=I_{\mathrm{mp}}$ and $V=V_{\mathrm{mp}}$ at maximum power point [48]. By substituting these expressions in (7), it yields

$$
I_{\mathrm{sc}, r}=I_{L, r}-I_{o, r}\left[e^{\left(\xi_{r} I_{\mathrm{sc}, r} R_{s}\right)}-1\right]
$$

where

$$
\begin{gathered}
\xi_{r}=\frac{q}{\lambda k T_{c, r}}, \\
I_{L, r}-I_{o, r}\left[e^{\left(\xi_{r} V_{\mathrm{oc}, r}\right)}-1\right]=0, \\
I_{\mathrm{mp}, r}=I_{L, r}-I_{o, r}\left[e^{\xi_{r}\left(V_{\mathrm{mp}, r}+I_{\mathrm{mp}, r} R_{s}\right)}-1\right] .
\end{gathered}
$$

The reverse saturation current $\left(I_{o}\right)$ is a very small quantity on the order of $10^{-5}$ to $10^{-6} \mathrm{~A}$ [47]. It lessens the influence of the exponential term in (11). Hence, it is assumed to be equivalent to $I_{\mathrm{sc}}$ [32]. One more generalization can be made regarding the first term in (13) and (14), which could be ignored. Regardless of the system size, the exponential term is much greater than the first term. Thus, the equations become

$$
\begin{gathered}
I_{L, r} \cong I_{\mathrm{sc}, r}, \\
I_{\mathrm{sc}, r}-I_{o, r}\left[e^{\left(\xi_{r} I_{\mathrm{sc}, r} R_{s}\right)}\right] \cong 0, \\
I_{\mathrm{mp}, r} \cong I_{L, r}-I_{o, r}\left[e^{\xi_{r}\left(V_{\mathrm{mp}, r}+I_{\mathrm{mp}, r} R_{s}\right)}\right] .
\end{gathered}
$$

Solving (16) for reverse saturation current at reference conditions, $\left(I_{o, r}\right)$ is obtained as

$$
I_{o, r}=I_{\mathrm{sc}, r}\left[e^{-\left(\xi_{r} V_{\mathrm{oc}, r}\right)}\right] .
$$

By substituting the value of reverse saturation current at reference conditions $\left(I_{o, r}\right)$ from (18) into (17), it yields

$$
I_{\mathrm{mp}, r} \cong I_{\mathrm{sc}, r}-I_{\mathrm{sc}, r}\left[e^{\xi_{r}\left(V_{\mathrm{mp}, r}-V_{\mathrm{oc}, r}+I_{\mathrm{mp}, r} R_{s}\right)}\right] .
$$

The Equation (17) can also be solved for $\xi_{r}$, which is given as

$$
\xi_{r}=\frac{\ln \left(1-I_{\mathrm{mp}, r} / I_{\mathrm{sc}, r}\right)}{V_{\mathrm{mp}, r}-V_{\mathrm{oc}, r}+I_{\mathrm{mp}, r} R_{s}} .
$$

Finally, the value of the shape factor $(\lambda)$ can be obtained by comparing (12) and (20) as

$$
\lambda=\frac{q\left(V_{\mathrm{mp}, r}-V_{\mathrm{oc}, r}+I_{\mathrm{mp}, r} R_{s}\right)}{k T_{c, r} \ln \left(1-I_{\mathrm{mp}, r} / I_{\mathrm{sc}, r}\right)} .
$$

2.1.4. Series Resistance $\left(R_{s}\right)$. The series resistance $\left(R_{s}\right)$ is an essential parameter when the module is not operating near the reference conditions. This characterizes the internal losses due to current flow inside the each cell and in linkages between cells. It alters the shape of $I-V$ curve near optimum power point and open circuit voltage; however, its effect is small $[29,36] . I-V$ curve without considering $R_{s}$ would be somewhat dissimilar than the curves outlined including its value. On the basis of annual simulation, the predicted power output from PV systems will be $5 \%$ to $8 \%$ lower when correct series resistance is not used $[32,51]$. It can be determined as

$$
\left.\frac{d V}{d I}\right|_{V_{\mathrm{oc}, r}}-R_{s}=0 .
$$

To obtain differential coefficient for (22), first the current (I) can be extracted explicitly as a function of voltage $(V)$ by using Lambert W function from (7) and is expressed as

$$
I=\left(I_{L}+I_{o}\right)-\frac{W\left(\xi R_{s} e^{\xi\left(V+I_{L} R_{s}+I_{o} R_{s}\right)}\right)}{\xi R_{s}} .
$$

By differentiating (23) with respect to $V$ and taking its reciprocal at $V=V_{\mathrm{oc}, r}$ and $I_{L}=I_{L, r}$ and substituting into (22), it gives

$$
\frac{W\left(\xi R_{s} I_{o} e^{\xi\left(V_{\mathrm{oc}, r}+I_{L, r} R_{s}+I_{o} R_{s}\right)}\right)}{\left[1+W\left(\xi R_{s} I_{o} e^{\xi\left(V_{\mathrm{oc}, r}+I_{L, r} R_{s}+I_{o} R_{s}\right)}\right)\right] R_{s}}-R_{s}=0 .
$$


A number of simplifications have been made in order to solve (24) analytically for $R_{s}$. For example, $I_{o}$ is usually taken in the order of $10^{-5}$ to $10^{-6}$ [47]. Its value for this study was taken as the order of $10^{-6}$. Similarly, the values of $I_{L, r}$ and $V_{\text {oc }, r}$ were taken from the manufacturers data. The expression for $R_{s}$ is obtained based on the above simplifications and by putting the value of $\xi$ in (24) as

$$
\begin{aligned}
& R_{s} \\
& =1.8 \operatorname{Re}\left(\frac{T_{c} W\left(-1.5 \times 10^{7} e^{0.022\left(47+\left(1.7 \times 10^{5} / T_{c}\right)\right)}\right)}{T_{c} W\left(-1.5 \times 10^{7} e^{0.022\left(47+\left(1.7 \times 10^{5} / T_{c}\right)\right)}\right)+4400}\right),
\end{aligned}
$$

where $\mathrm{Re}$ represents the real part, because the negative expression inside the Lambert $\mathrm{W}$ function results in a complex number. However, in practical problems only real values are to be considered.

2.2. Determination of Optimum Power Output Parameters of Proposed Model. The optimum power output parameters of model were determined by deriving the equations for current $(I)$ and voltage $(V)$ by putting the values of unknown parameters, namely, $I_{L}, I_{o}, R_{s}$, and $\lambda$, in the respective equations. The power $(P)$ is the product of current $(I)$ and voltage $(V)[48]$; therefore, it can be expressed as

$$
P=I V
$$

By substituting $I$ from (23) into (26), the value of $P$ is computed as [52]

$$
P=\left\{\left(I_{L}+I_{o}\right)-\frac{W\left[\xi R_{s} e^{\xi\left(V+I_{L} R_{s}+I_{o} R_{s}\right)}\right]}{\xi R_{s}}\right\} V .
$$

Mathematically, the optimum power occurs at the point $V_{\text {max }}$ of $P-V$ curve, where the slope of tangent line is equal to zero as follows:

$$
\left.\frac{d P}{d V}\right|_{V_{\max }}=0
$$

By differentiating (27) with respect to voltage $(V)$ and taking the R.H.S equal to zero,

$$
\begin{aligned}
& \frac{W\left[\xi R_{s} I_{o} e^{\xi\left(V+I_{L} R_{s}+I_{o} R_{s}\right)}\right] V}{\left\{1+W\left[\xi R_{s} I_{o} e^{\xi\left(V+I_{L} R_{s}+I_{o} R_{s}\right)}\right]\right\} R_{s}}+\frac{1}{\xi R_{s}} \\
& \quad \times\left\{W\left[\xi R_{s} I_{o} e^{\xi\left(V+I_{L} R_{s}+I_{o} R_{s}\right)}\right]-\xi R_{s}\left(I_{L}+I_{o}\right)\right\}=0 .
\end{aligned}
$$

Newton-Raphson method is applied to (29) in order to find the critical value of $V$ for $V_{\max }$. The value of $V_{\max }$ is substituted into (27) in order to solve the maximum power $\left(P_{\max }\right)$. Consider

$$
P_{\max }=\left\{\left(I_{L}+I_{o}\right)-\frac{W\left[\xi R_{s} e^{\xi\left(V_{\max }+I_{L} R_{s}+I_{o} R_{s}\right)}\right]}{\xi R_{s}}\right\} V_{\max } .
$$

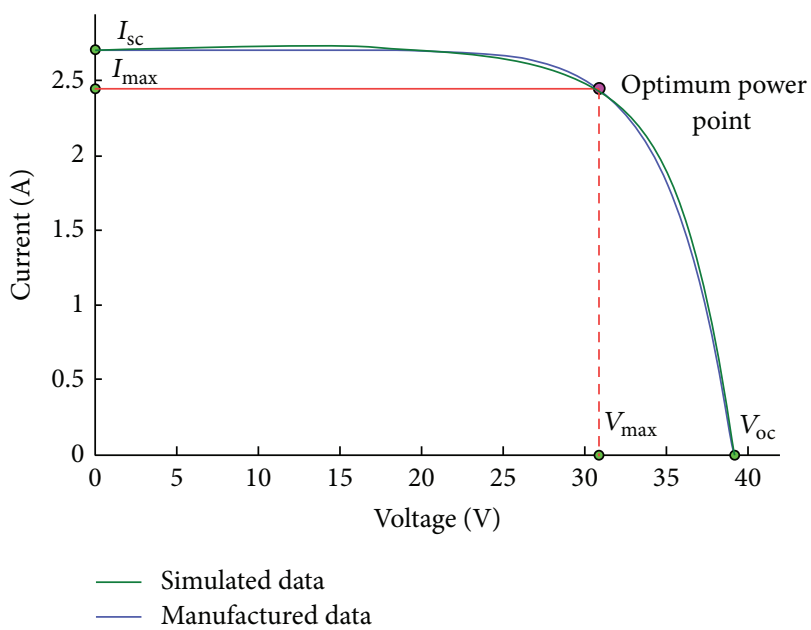

Figure 2: Typical $I-V$ characteristic curve of a PV module.

Consequently, the desired maximum current $\left(I_{\max }\right)$ can be obtained from (30) by dividing the maximum power $\left(P_{\max }\right)$ with maximum voltage $\left(V_{\max }\right)$. Consider

$$
I_{\max }=\frac{P_{\max }}{V_{\max }} .
$$

\section{Simulation of $I-V$ and $P-V$ Characteristic Curves of a Selected PV Module}

The familiarity of current and voltage relationship of photovoltaic modules under real operating conditions is essential for the determination of their power output. Normally, the cells are mounted in modules, and multiple modules are used in arrays to get desired power output. Individual modules may have cells connected in series and parallel combinations to obtain the required current and voltage. Similarly, the array of modules may be arranged in series and parallel connections. When the cells or modules are connected in series, the voltage is additive, and when they are attached in parallel, the currents are additive [52-56]. The power output of PV modules could be predicted from the behavior of current-voltage, $I-V$, and power-voltage, $P-V$, characteristic curves. The current-voltage and power-voltage characteristic curves are graphically shown in Figures 2 to 9.

The current-voltage, $I-V$, characteristic of a typical PV module is shown in Figure 2. When the output voltage $V=0$, the current is the short circuit current $\left(I_{\mathrm{sc}}\right)$ and when the current $I=0$, the output voltage is the open circuit voltage $\left(V_{\text {oc }}\right)$. Mostly the current decreases slowly at a certain point and then decreases rapidly to the open circuit conditions. The power as a function of voltage is given in Figure 3. The maximum power that can be obtained corresponds to the rectangle of maximum area under $I-V$ curve. At the optimum power point the power is $P_{\mathrm{mp}}$, the current is $I_{\mathrm{mp}}$, and the voltage is $V_{\mathrm{mp}}$. Ideally, the cells would always operate at the optimum power point that matches the $I-V$ characteristic of the load. Hence, the load matching is essential for extracting the maximum power from the solar photovoltaic modules. 


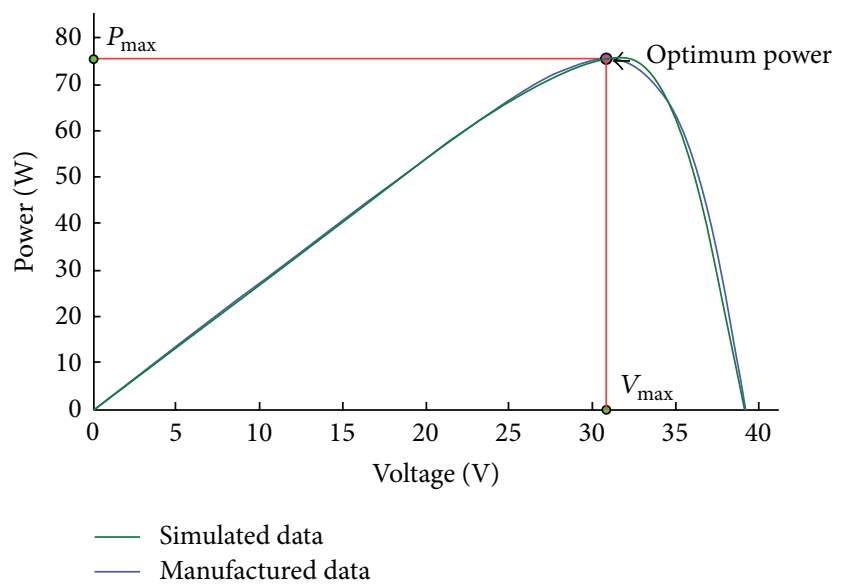

FIgure 3: Typical $P-V$ characteristic curve of a PV module.

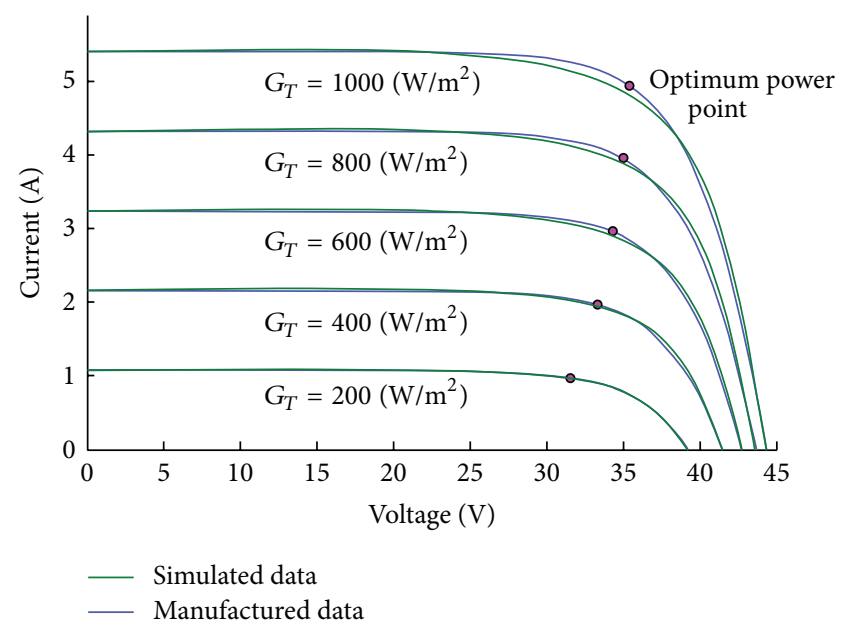

FIGURE 4: $I$ - $V$ characteristic curves at various solar radiation levels.

Therefore, the maximum power point tractors are preferred to optimize the output power from solar PV systems.

$I-V$ characteristic curves at various solar irradiation levels and temperatures are shown in Figures 4 and 5, respectively. The locus of maximum power point is indicated on the curves. The short circuit current increases in proportion to the solar radiation while the open circuit voltage increases logarithmically with solar radiation. As long as the curved portion of the $I-V$ characteristic does not intersect, the short circuit current is nearly proportional to the incident solar radiation. If the incident solar radiation is assumed to be a fixed spectral distribution, the short circuit current can be used as a measure of incident solar radiation. $I-V$ characteristics curves for the combination of irradiance and temperatures are illustrated in Figure 6. It was observed that the temperature linearly decreases the output voltage as compared to current. Consequently, the decrease of voltage lowers the power output of PV module at constant solar irradiation level. However, the effect of temperature is small on short circuit current but increases with the increase of incident solar radiation.

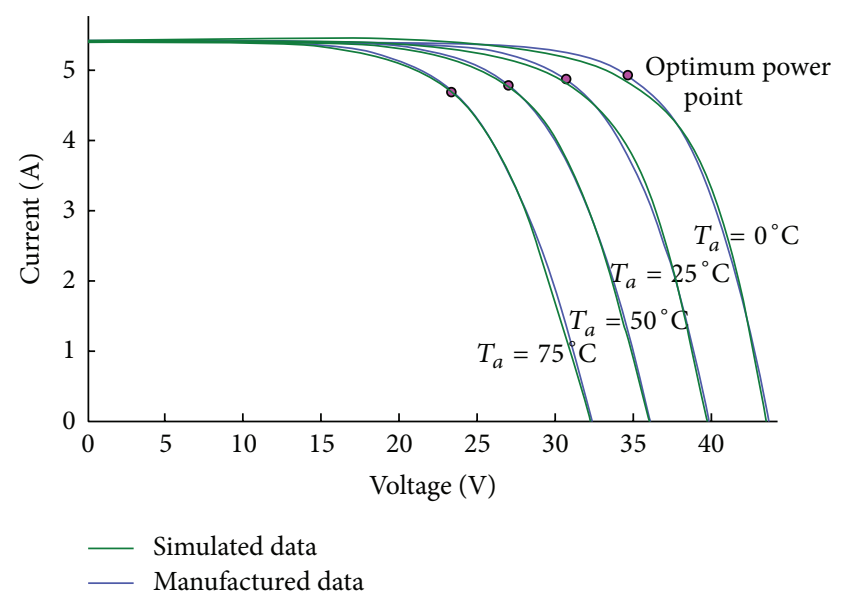

FIGURE 5: $I-V$ characteristic curves at various temperatures.

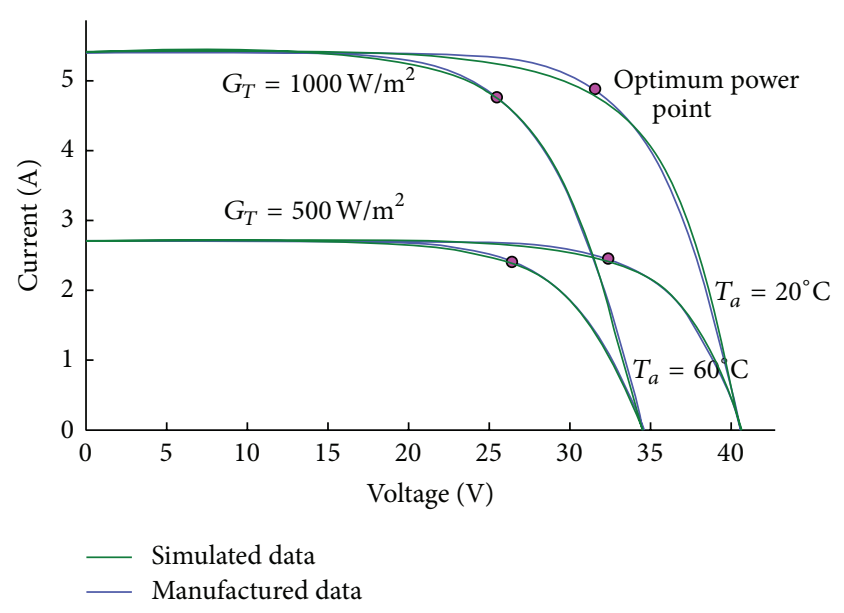

FIGURE 6: $I-V$ characteristic curves for various set of solar radiation and temperature.

The $P-V$ characteristics curves for various solar irradiation levels at constant temperature of $25^{\circ} \mathrm{C}$ and at several temperatures with constant solar irradiance of $1000 \mathrm{~W} / \mathrm{m}^{2}$ is illustrated in Figures 7 and 8, respectively. Increasing temperature leads to decreasing the open circuit voltage and slightly increasing the short circuit current. Operating of cell temperature at that region of the curve leads to a significant power reduction at high temperatures. The $P-V$ characteristics curves for the combination of irradiance and temperatures are shown in Figure 9.

The power output of photovoltaic module by formulated model gave $\mathrm{a} \pm 2 \%$ error when compared with the rated power of PV module provided by manufacturers on average basis. However, at higher solar radiation and temperature values, the model simulated results were somehow deviated from the rated power of PV module. Since, the shunt resistance $\left(R_{\mathrm{sh}}\right)$ was assumed to be infinity in the proposed model. It was found from the analysis that the increase of temperature and decrease of incident solar radiation levels lead to lower power output and vice versa. The power output from PV modules 


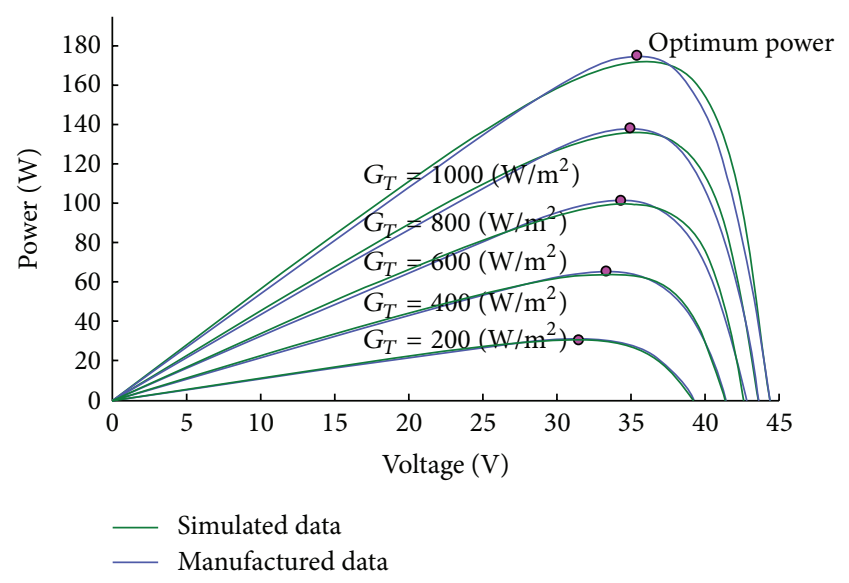

Figure 7: $P-V$ characteristic curve at constant temperature of $25^{\circ} \mathrm{C}$.

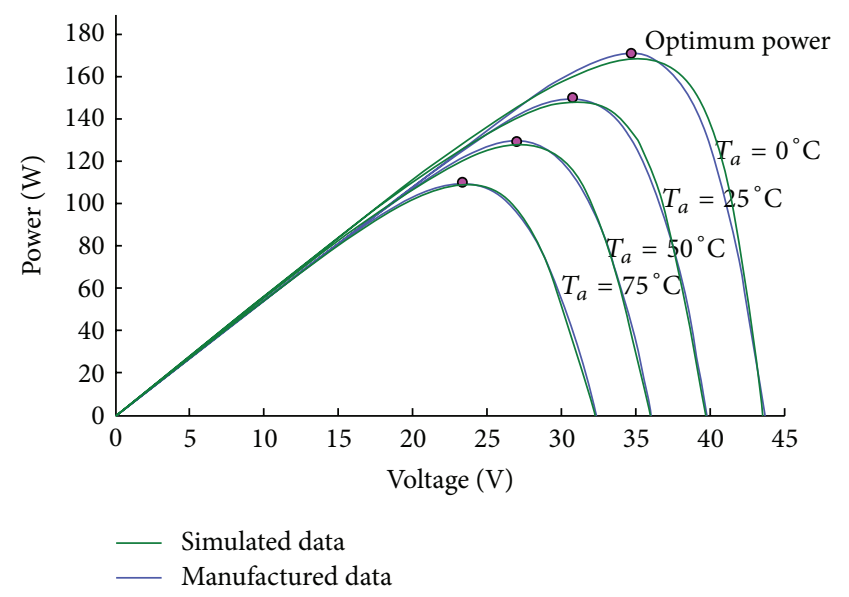

FIGURE 8: $P-V$ characteristic curve at constant solar radiation of $1000 \mathrm{~W} / \mathrm{m}^{2}$.

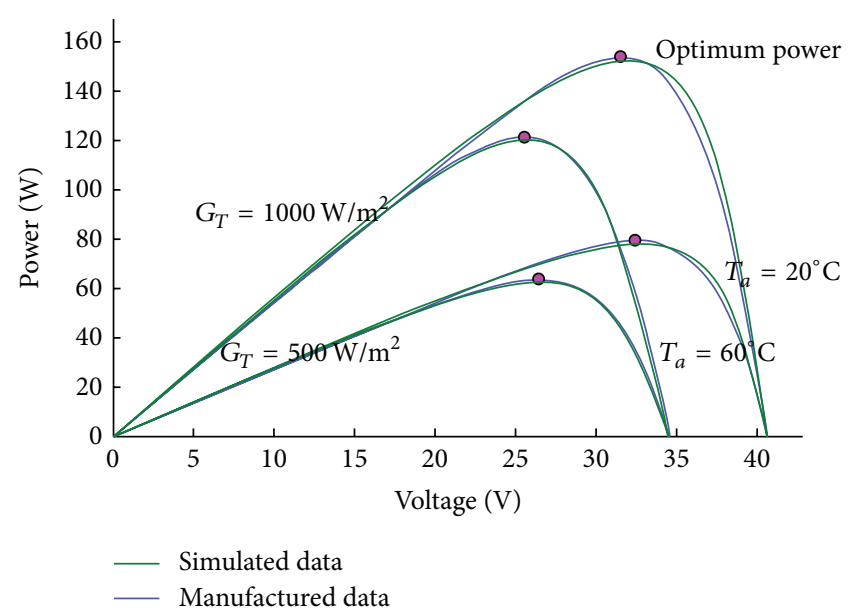

FIgURE 9: $P-V$ characteristic curve at various set of solar radiation and temperature. approaches zero, if the amount of solar radiation tends to decrease and the temperature goes up.

\section{Conclusions}

The proposed mathematical model is formulated by integration of both analytical and numerical methods. The required parameters of current-voltage $(I-V)$ curve such as the light-generated current, diode reverse saturation current, shape parameter, and the series resistance are computed analytically. The expression for output current from PV module is determined explicitly by Lambert $\mathrm{W}$ function and voltage output is computed numerically by Newton-Raphson method. The main contribution of this study is algebraic derivation of equations for the shape factor $(\lambda)$ which involve the ideality factor $(A)$ and the series resistance $\left(R_{s}\right)$ of single diode model of PV module power output. These equations will help to find out the predicted power output of PV modules in precise and convenient manner.

The current-voltage $(I-V)$ and the power-voltage $(P-V)$ characteristic curves obtained from the proposed model were matching with the curves drawn from the PV module at standard test conditions. The variation of incident solar radiation and temperature were found to be the main cause of modifications in the amount of PV module power output. A linear relationship between the power output of PV module and the amount of incident solar radiation were observed if other factors were kept constant.

The estimated results of the proposed model are validated by PV module rated power output provided by manufacturer, which gave a $\pm 2 \%$ error. The model is found to be more practical in terms of the number of variables used and predicted satisfactory performance of PV modules.

\section{Nomenclature}

$S_{T}$ : absorbed solar radiation, $\mathrm{W} / \mathrm{m}^{2}$

$k$ : Boltzmann's constant, $1.381 \times 10^{-23} \mathrm{~J} / \mathrm{K}$

$T_{c}$ : Cell temperature at actual conditions, $\mathrm{K}$

I: $\quad$ Current output of cell, A

$I_{D}$ : Diode current or dark current, A

$D$ : Diode diffusion factor, -

$I_{o}$ : Diode reverse saturation current, A

$A$ : Ideality factor, 1 for ideal diodes and between 1 and 2 for real diodes

$W$ : Lambert $\mathrm{W}$ function, -

$I_{L}: \quad$ Light-generated current, $\mathrm{A}$

$\varepsilon_{g}$ : Material band gap energy, $\mathrm{eV}, 1.12 \mathrm{eV}$ for silicon and $1.35 \mathrm{eV}$ for gallium arsenide

$I_{\mathrm{mp}}$ : Maximum current of PV module, A

$P_{\mathrm{mp}}$ : Maximum power of $\mathrm{PV}$ module, $\mathrm{W}$

$V_{\mathrm{mp}}$ : Maximum voltage of $\mathrm{PV}$ module, $\mathrm{V}$

$N_{\text {cs }}$ : Number of cells in series, -

$V_{\mathrm{oc}}$ : Open circuit voltage of PV module, $\mathrm{V}$

$\xi: \quad$ Parameter, $q / k T_{c} \lambda$

$R_{s}$ : Series resistance, $\Omega$

$\lambda$ : $\quad$ Shape factor of $I-V$ curve, - 
$I_{\text {sc }}:$ Short circuit current of PV module, A

$R_{\text {sh }}$ : Shunt resistance, $\Omega$

$\mu_{I_{s c}}$ : Temperature coefficient of short circuit current, -

$\mu_{V_{o c}}:$ Temperature coefficient of voltage, $\mathrm{V} / \mathrm{K}$

$V: \quad$ Voltage output of cell, $\mathrm{V}$

$G_{T}:$ Solar radiation, $\mathrm{W} / \mathrm{m}^{2}$

$q$ : $\quad$ Electron charge, $1.602 \times 10^{-19} \mathrm{C}$

$T_{a}$ : Ambient temperature, ${ }^{\circ} \mathrm{C}$.

\section{The Subscript}

$r$ : In any notation the corresponding value of parameter at reference conditions.

\section{Conflict of Interests}

The authors declare that there is no conflict of interests regarding the publication of this paper.

\section{References}

[1] W. Durisch, D. Tille, A. Wörz, and W. Plapp, "Characterisation of photovoltaic generators," Applied Energy, vol. 65, no. 1-4, pp. 273-284, 2000.

[2] A. Q. Jakhrani, A. K. Othman, A. R. H. Rigit, S. R. Samo, and S. R. Kamboh, "A novel analytical model for optimal sizing of standalone photovoltaic systems," Energy, vol. 46, no. 1, pp. 675682, 2012.

[3] A. N. Celik, "A simplified model based on clearness index for estimating yearly performance of hybrid pv energy systems," Progress in Photovoltaics: Research and Applications, vol. 10, no. 8, pp. 545-554, 2002.

[4] A. H. Fanney and B. P. Dougherty, "Building integrated photovoltaic test facility," Journal of Solar Energy Engineering, vol. 123, no. 3, pp. 194-199, 2001.

[5] M. A. Green, "Short communication: price/efficiency correlations for 2004 photovoltaic modules," Progress in Photovoltaics: Research and Applications, vol. 13, pp. 85-87, 2005.

[6] A. Q. Jakhrani, A. K. Othman, A. R. H. Rigit, and S. R. Samo, "Model for estimation of global solar radiation in Sarawak, Malaysia," World Applied Sciences Journal, vol. 14, pp. 83-90, 2011.

[7] A. Q. Jakhrani, A. K. Othman, A. R. H. Rigit, and S. R. Samo, "Assessment of solar and wind energy resources at five typical locations in Sarawak," Journal of Energy \& Environment, vol. 3, pp. 8-13, 2012.

[8] R. Ramaprabha and B. L. Mathur, "Development of an improved model of SPV cell for partially shaded solar photovoltaic arrays," European Journal of Scientific Research, vol. 47, no. 1, pp. 122-134, 2010.

[9] J. A. R. Hernanz, J. J. C. ampayo Martin, I. Z. Belver, J. L. Lesaka, E. Z. Guerrero, and E. P. Perez, "Modelling of photovoltaic module," in Proceedings of the International Conference on Renewable Energies and Power Quality (ICREPQ '10), Granada, Spain, March 2010.

[10] R. B. Andrews, A. Pollard, and J. M. Pearce, "Improved parametric empirical determination of module short circuit current for modelling and optimization of solar photovoltaic systems," Solar Energy, vol. 86, pp. 2240-2254, 2012.
[11] R. L. Chakrasali, V. R. Sheelavant, and H. N. Nagaraja, "Network approach to modeling and simulation of solar photovoltaic cell," Renewable and Sustainable Energy Reviews, vol. 21, pp. 84-88, 2013.

[12] A. Chouder, S. Silvestre, N. Sadaoui, and L. Rahmani, "Modeling and simulation of a grid connected PV system based on the evaluation of main PV module parameters," Simulation Modelling Practice and Theory, vol. 20, no. 1, pp. 46-58, 2012.

[13] A. Chouder, S. Silvestre, B. Taghezouit, and E. Karatepe, "Monitoring, modeling and simulation of PV systems using LabVIEW,' Solar Energy, vol. 91, pp. 337-349, 2013.

[14] A. Jain and A. Kapoor, "A new approach to study organic solar cell using Lambert W-function," Solar Energy Materials and Solar Cells, vol. 86, no. 2, pp. 197-205, 2005.

[15] A. Jain, S. Sharma, and A. Kapoor, "Solar cell array parameters using Lambert W-function," Solar Energy Materials and Solar Cells, vol. 90, no. 1, pp. 25-31, 2006.

[16] A. Ortiz-Conde, F. J. García Sánchez, and J. Muci, "New method to extract the model parameters of solar cells from the explicit analytic solutions of their illuminated I-V characteristics," Solar Energy Materials and Solar Cells, vol. 90, no. 3, pp. 352-361, 2006.

[17] D. Picault, B. Raison, S. Bacha, J. de la Casa, and J. Aguilera, "Forecasting photovoltaic array power production subject to mismatch losses," Solar Energy, vol. 84, no. 7, pp. 1301-1309, 2010.

[18] Y. Chen, X. Wang, D. Li, R. Hong, and H. Shen, "Parameters extraction from commercial solar cells I-V characteristics and shunt analysis," Applied Energy, vol. 88, no. 6, pp. 2239-2244, 2011.

[19] H. Fathabadi, "Novel neural-analytical method for determining silicon/plastic solar cells and modules characteristics," Energy Conversion and Management, vol. 76, pp. 253-259, 2013.

[20] Y. Chen, X. Wang, D. Li, R. Hong, and H. Shen, "Parameters extraction from commercial solar cells I-V characteristics and shunt analysis," Applied Energy, vol. 88, no. 6, pp. 2239-2244, 2011.

[21] Krismadinata, N. A. Rahim, H. W. Ping, and J. Selvaraj, "Photovoltaic module modeling using simulink/matlab," Procedia Environmental Sciences, vol. 17, pp. 537-546, 2013.

[22] F. Lu, S. Guo, T. M. Walsh, and A. G. Aberle, "Improved PV module performance under partial shading conditions," Energy Procedia, vol. 33, pp. 248-255, 2013.

[23] A. Mellit, S. Sağlam, and S. A. Kalogirou, "Artificial neural network-based model for estimating the produced power of a photovoltaic module," Renewable Energy, vol. 60, pp. 71-78, 2013.

[24] G. K. Singh, "Solar power generation by PV, (photovoltaic) technology: a review," Energy, vol. 3, pp. 1-13, 2013.

[25] D. Thevenard and S. Pelland, "Estimating the uncertainty in long-term photovoltaic yield predictions," Solar Energy, vol. 91, pp. 432-445, 2013.

[26] H. Tian, F. Mancilla-David, K. Ellis, E. Muljadi, and P. Jenkins, "A cell-to-module-to-array detailed model for photovoltaic panels," Solar Energy, vol. 86, pp. 2695-2706, 2012.

[27] M. C. D. Vincenzo and D. Infield, "Detailed PV array model for non-uniform irradiance and its validation against experimental data," Solar Energy, vol. 97, pp. 314-331, 2013.

[28] G. H. Yordanov, O.-M. Midtgård, and T. O. Saetre, "Series resistance determination and further characterization of c-Si PV modules," Renewable Energy, vol. 46, pp. 72-80, 2012. 
[29] W. De Soto, S. A. Klein, and W. A. Beckman, "Improvement and validation of a model for photovoltaic array performance," Solar Energy, vol. 80, no. 1, pp. 78-88, 2006.

[30] E. Karatepe, M. Boztepe, and M. Colak, "Neural network based solar cell model," Energy Conversion and Management, vol. 47, no. 9-10, pp. 1159-1178, 2006.

[31] Y.-C. Kuo, T.-J. Liang, and J.-F. Chen, "Novel maximum-powerpoint-tracking controller for photovoltaic energy conversion system," IEEE Transactions on Industrial Electronics, vol. 48, no. 3, pp. 594-601, 2001.

[32] R. Chenni, M. Makhlouf, T. Kerbache, and A. Bouzid, "A detailed modeling method for photovoltaic cells," Energy, vol. 32, no. 9, pp. 1724-1730, 2007.

[33] A. Wagner, Peak-Power and Internal Series Resistance Measurement under Natural Ambient Conditions, EuroSun, Copenhagen, Denmark, 2000.

[34] M. Chegaar, G. Azzouzi, and P. Mialhe, "Simple parameter extraction method for illuminated solar cells," Solid-State Electronics, vol. 50, no. 7-8, pp. 1234-1237, 2006.

[35] K. Bouzidi, M. Chegaar, and A. Bouhemadou, "Solar cells parameters evaluation considering the series and shunt resistance," Solar Energy Materials and Solar Cells, vol. 91, no. 18, pp. 1647-1651, 2007.

[36] J. C. Ranuárez, A. Ortiz-Conde, and F. J. García Sánchez, "A new method to extract diode parameters under the presence of parasitic series and shunt resistance," Microelectronics Reliability, vol. 40, no. 2, pp. 355-358, 2000.

[37] M. A. De Blas, J. L. Torres, E. Prieto, and A. García, "Selecting a suitable model for characterizing photovoltaic devices," Renewable Energy, vol. 25, no. 3, pp. 371-380, 2002.

[38] D. Petreus, C. Frcas, and I. Ciocan, "Modelling and simulation of photovoltaic cells," Acta Technica Napocensis: ElectronicaTelecomunicatii, vol. 49, pp. 42-47, 2008.

[39] V. D. Dio, D. La Cascia, R. Miceli, and C. Rando, "A mathematical model to determine the electrical energy production in photovoltaic fields under mismatch effect," in Proceedings of the International Conference on Clean Electrical Power (ICCEP '09), pp. 46-51, Capri, Italy, June 2009.

[40] W. Kim and W. Choi, "A novel parameter extraction method for the one-diode solar cell model," Solar Energy, vol. 84, no. 6, pp. 1008-1019, 2010.

[41] D. Petreus, I. Ciocan, and C. Farcas, An Improvement on Empirical Modelling of Photovoltaic Cells, ISSE, Madrid, Spain, 2008.

[42] M. S. Benghanem and N. A. Saleh, "Modeling of photovoltaic module and experimental determination of serial resistance," Journal of Taibah University for Science, vol. 1, pp. 94-105, 2009.

[43] A. N. Celik, "Effect of different load profiles on the loss-of-load probability of stand-alone photovoltaic systems," Renewable Energy, vol. 32, no. 12, pp. 2096-2115, 2007.

[44] Q. Kou, S. A. Klein, and W. A. Beckman, "A method for estimating the long-term performance of direct-coupled PV pumping systems," Solar Energy, vol. 64, no. 1-3, pp. 33-40, 1998.

[45] J. A. Duffie and W. A. Beckman, Solar Engineering of Thermal Processes, John Wiley \& Sons, 3rd edition, 2006.

[46] A. H. Fanney, B. P. Dougherty, and M. W. Davis, "Evaluating building integrated photovoltaic performance models," in Proceedings of the 29th IEEE Photovoltaic Specialists Conference (PVSC '02), New Orleans, La, USA, May 2002.

[47] R. L. Boylestad, L. Nashelsky, and L. Li, Electronic Devices and Circuit Theory, Prentice-Hall, 10th edition, 2009.
[48] E. Saloux, A. Teyssedou, and M. Sorin, "Explicit model of photovoltaic panels to determine voltages and currents at the maximum power point," Solar Energy, vol. 85, no. 5, pp. 713722, 2011.

[49] J. Crispim, M. Carreira, and C. Rui, "Validation of photovoltaic electrical models against manufacturers data and experimental results," in Proceedings of the International Conference on Power Engineering, Energy and Electrical Drives (POWERENG '07), pp. 556-561, Setubal, Portugal, April 2007.

[50] F. M. González-Longatt, Model of Photovoltaic Module in Matlab, II CIBELEC, Puerto La Cruz, Venezuela, 2006.

[51] D. Sera and R. Teodorescu, "Robust series resistance estimation for diagnostics of photovoltaic modules," in Proceedings of the 35th Annual Conference of the IEEE Industrial Electronics Society (IECON '09), pp. 800-805, Porto, Portugal, November 2009.

[52] A. Q. Jakhrani, A. K. Othman, A. R. H. Rigit, R. Baini, S. R. Samo, and L. P. Ling, "Investigation of solar photovoltaic module power output by various models," NED University Journal of Research, pp. 25-34, 2012.

[53] A. Q. Jakhrani, A. K. Othman, A. R. H. Rigit, and S. R. Samo, "Comparison of solar photovoltaic module temperature models," World Applied Sciences Journal, vol. 14, pp. 1-8, 2011.

[54] A. Q. Jakhrani, A. K. Othman, A. R. H. Rigit, and S. R. Samo, "Determination and comparison of different photovoltaic module temperature models for Kuching, Sarawak," in Proceedings of the IEEE 1st Conference on Clean Energy and Technology (CET '11), pp. 231-236, Kuala Lumpur, Malaysia, June 2011.

[55] A. Q. Jakhrani, S. R. Samo, A. R. H. Rigit, and S. A. Kamboh, "Selection of models for calculation of incident solar radiation on tilted surfaces," World Applied Sciences Journal, vol. 22, no. 9, pp. 1334-1341, 2013.

[56] A. Q. Jakhrani, A. K. Othman, A. R. H. Rigit, S. R. Samo, and S. A. Kamboh, "Sensitivity analysis of a standalone photovoltaic system model parameters," Journal of Applied Sciences, vol. 13, no. 2, pp. 220-231, 2013. 

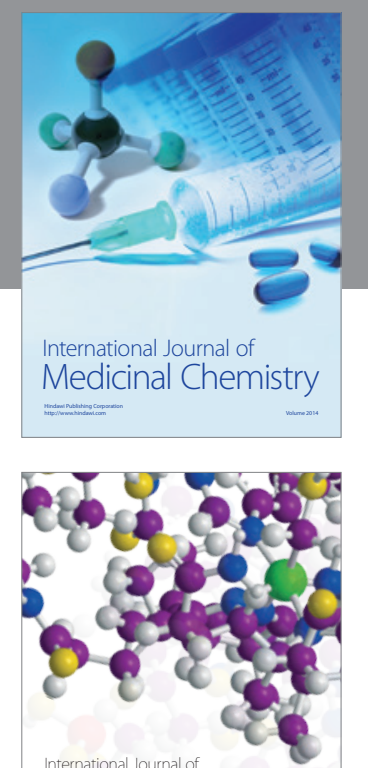

\section{Carbohydrate} Chemistry

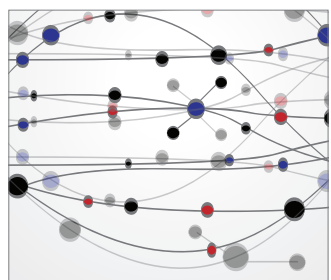

The Scientific World Journal
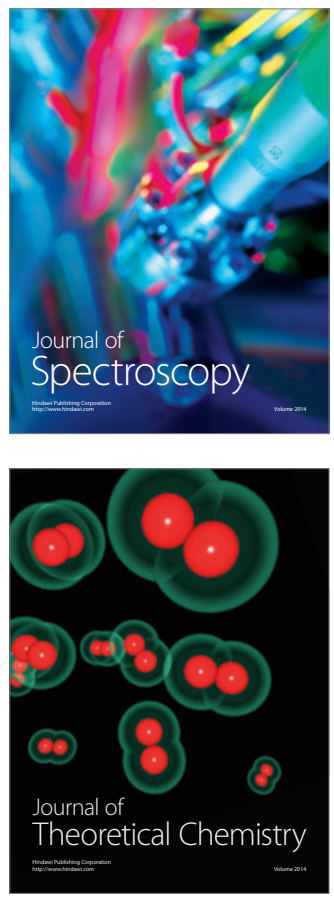
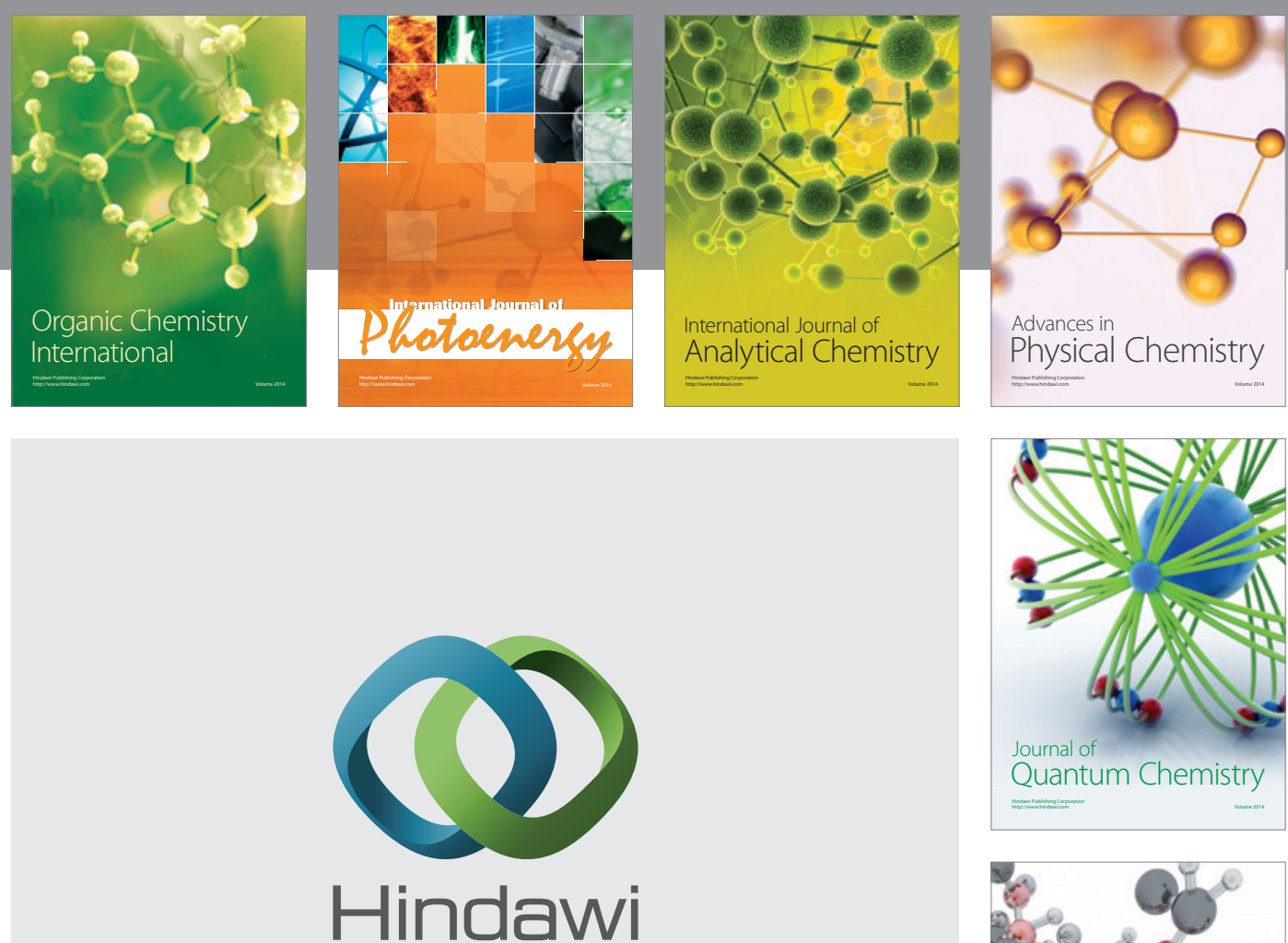

Submit your manuscripts at

http://www.hindawi.com

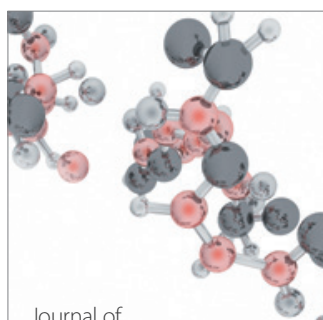

Analytical Methods

in Chemistry

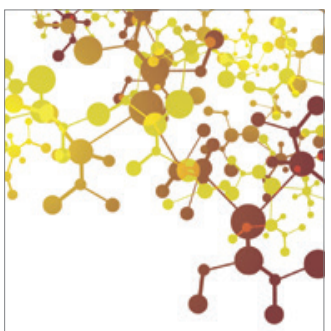

Journal of

Applied Chemistry

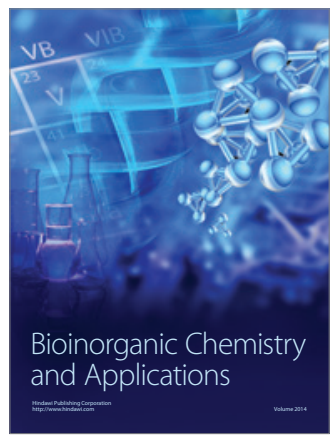

Inorganic Chemistry
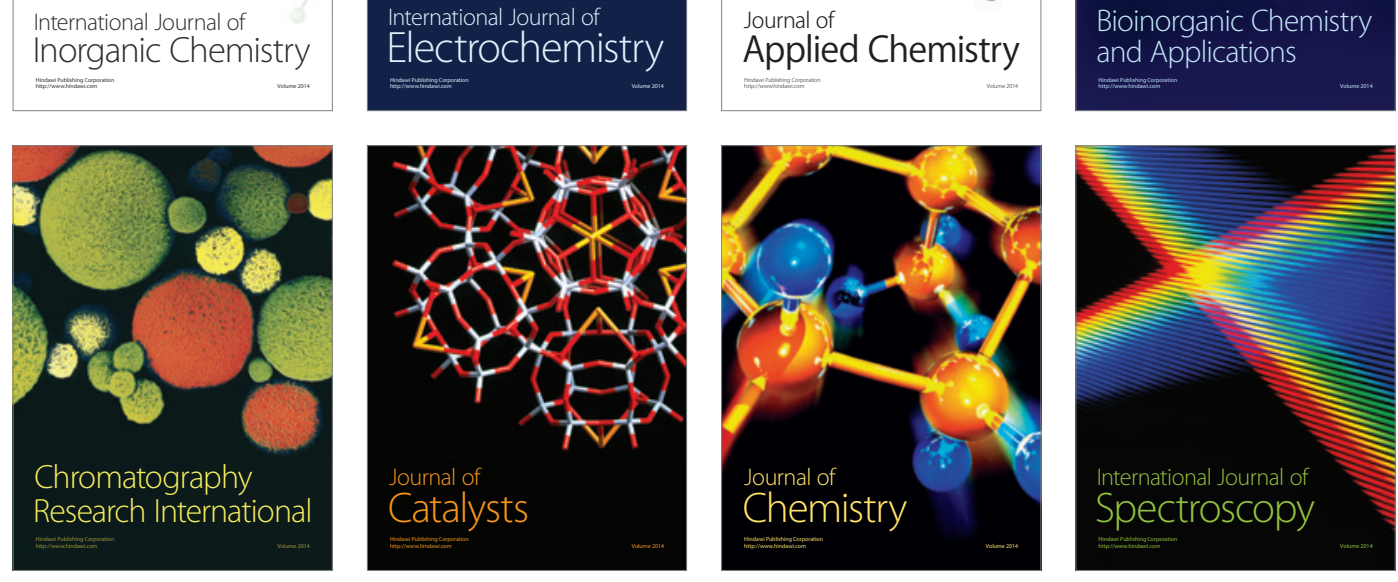